\title{
GÜNÜMÜZDE GAZETELER VE GAZETE OKUMA
}

\section{Dr. Oya TOKGÖz}

\section{I - GENEL OLARAK GAZETECILIK HIZMETLERI}

Çağımızda basının yanında radyo ve televizyonun da gazetecilik yapması dolayısıyla, dünyamızda en uzun geçmişi bulunan gazetelerin okuyucu bulması bugün üzerinde durulan en önemli sorunlardan bir tanesi olmuștur. Radyo ve televizyondan verilen haberleri duyan ve seyreden kişiler yine de gazeteleri büyük bir ilgiyle okuyacaklar midır? Yoksa, gazeteler, radyo ve televizyonun yanında ikinci plana $\mathrm{mi}$ itileceklerdir?

Aslında, göze hitap eden bir kitle haberleşme aracı olan gazetelerin verdikleri, yazdıkları, aracın yapısal özellikleri gözönüne alınırsa, belge niteliğini taşıdığından, kalıcılık özelliğine sahip bulunmaktadır. Bu yönden üzerinde durulması gereken en önemli sorun radyo ve televizyonun doğalarına has çekiciliği yanında, insanların ilgisini-çekecek şekilde gazetelerin nasıl hazırlanıp çıkarılacağıdır. Yani temel sorun: insanların bulup geliştirdiği gazeteyi, yeni çıkan kitle haberleşme araçları olan radyo ve televizyon yanında, yine insanlar için nasıl ilgi çeken bir araç olarak korumayı bașarabilmedir.

Uzun yillar hattâ yüzyıllarca kamu oyunu oluşturan, biçimlendiren, șekillendiren hattâ değiştiren tek araç olarak gazeteden bahsedilmiștir. Amerikalı yazarlardan Walter Lippmann ${ }^{1}$ ise ilk defa kamu oyu üzerinde yazdığı kitapta "gazete insanların hergün okuduğu tek kitaptır» demekten kendini alamamıștır. Ama, radyo ve televizyonun gelişmesiyle insanlar üzerinde fazlasıyla etkili bir araç olan gazetelerin bugün ikinci, hattâ plana düşmüş olduğu söylenmektedir.

(1) Walter Lippmann, Public Opinion, (MacMillian and Co. 1922). 
Gerek radyo, gerek televizyon, gerekse gazeteler ancak kişilerin boș zamanlarında faydalandıkları araçlardır. Bunlar, kișilerin monoton modern hayatlarına renk katmakta, onları haberdar et. mekte, eğlendirmektedirler. Bir yandan da, yaptıkları hizmetleri kullanmak kişiler için bir alışkanlık haline gelmiştir. Kişiler, gazete okumadan, radyo dinlemeden, televizyon izlemeden çalıșma günlerini tamamlanmış saymamaktadırlar. Daha bașka bir deyișle, kitle haberleşme araçlarından yararlanma, gönüllü bir işlem olarak yapilagelmektedir.

Gönüllüi bir işlem olmasına rağmen, televizyon seyretme, gazete okuma, radyo dinleme, kişilerin kendileri bakımından zorunlu olarak zaman ayırma durumunu da ortaya çıkarmıștır. Yani, bu araçların verdiklerinden az veya çok ölçüde yararlanma için kişi, bir bakıma kendini zorunlu saymaktadır. Bu konuyu ilk defa bilimsel şekilde ortaya koyan Bernard Berelson'un 1945'lerde gazetesız kalmak" sorunu olarak nitelendirdiği araștırması, ${ }^{2}$ aynı șekilde bugün radyo ve televizyon için de araştırılırsa, ilk araştırmanın sonuçları yönünde bulgular elde edilecektir. Kısacası, kişileri radyo, televizyon ve gazeteler öylesine etkilemektedirler ki, kișiler dünyayı ancak bunlar aracılığı ile algılayabilir hale gelmișlerdir.3

Yalnız yukarıdaki yargıdan sonra, kişiler ne kadar radyo dinle mektedirler, televizyon seyretmektedirler, gazete okumaktadirlar, aynı zamanda, neden devamlı olarak bunlara bașvurmaktadırlar sorularını da hemen arkasından sormak gerekmektedir. Bu soruların cevabını bulma, hem kișilerin kitle haberleșme araçlarının verdiklerine karşı ne kadar ilgi duyduklarını, hem de aynı araçların ne kadar kișiye ulașabildiklerini saptayabilmek bakimından önemlidir.

Radyo haberlerinde spikerin okuyarak sunduğu yazılı metinde yer yer yerinde kayda alınmış seslerin kullanılması, televizyonda ise haber olan olayların oluyormuș gibi resimlerle, filimlerle verilebilme olanakları, gazetelerin çok fazla hamle yapmasını zorunlu kılmıștır. Bol resim kullanma, renkli baskıya geçme, bașlık ların irileşmesi, sayfa düzeninin değişmesi, gazetecilikte yapılan değișikliklerin bazı örnekleridir. Hele radyo ve televizyonun, her

(2) Bernard Berelson, "What A Missing Newspaper Means?» Wilbur Schramm (der.) The Process and Effects of Mass Communication (Urbana: University of Illinois Press, 1954), s. 36-47.

(3) Marshall McLuhan, Understanding the Media: The Extensions of Men - (New York: The New American Library, 1964). 
bakımdan olduğu gibi habercilik yönünden de günün 24 saatinin belirli süreleri ile kısıtlı olması, yine gazeteciliğin emin adımlarla yürümesine engel olamamıştır. Bununla beraber esas sorun, radyo ve televziyon gibi kolay haber alma olanakları yanında okuma gibi zaman alan bir işlemi zorunlu kılan gazetelerin nasıl insanların ilgisini çekeceğidir.

Radyoyu dinlerken, televizyonu seyrederken kişinin bir iş yapma olanağı olmakla beraber, gazete okurken bu olanak hemen hemen ortadan kalkar duruma girmektedir. Bu durum da gazete okumada dikkatin radyo ve televizyona oranla daha fazla önemli olduğunu ortaya çıkarmaktadır. Insanoğlu gazete okurken dikkat sarfedeceğine göre, neleri seçecek neleri seçmeyecektir gibi bir soru dikkati tanımlayabilmk bakımından önemli olmaktadır.

Aslında, kișilerin, kișilikleri, yetiștikleri toplumsal ortam, beğenileri, birbirinden çok farklıdır. Bu yönden de boş zamanlarında gönülliu olarak kitle haberleșme araçlarını kullanmaları da birbirinden farklı olacaktır. Zaten, kitle haberleşme araçlarının verdiği haberlerde olaylar olduktan sonra, olayları okuyucuya, dinleyiciye, seyirciye anlamlı hale getirebilecek șekilde esas .çerçevesi içinde yeniden düzenlenmiş olaylardır. ${ }^{4}$

Haberlerde, olmuş olayların, muhabirler tarafından anlaşılır bir șekilde haber alınma suretiyle, yine anlamlı bir şekilde izleyicilere haber verme şeklinde sunulması olmaktadır. 5 Böylelikle, kişi lerin zihninde haber kavramı yerleşmekle beraber, aynı zamanda daha önce kendisine seçilerek hazırlanmıș haberler arasından hangilerini seçmesi gibi bir durum belirmektedir. Bir yandan, gazeteler radyo ve televizyon verdikleri haberler bakımından aralarında kimler benden daha çok yararlanacak diye rekabet ederlerken, izleyici durumunda bulunanlar da gönülliu olarak izlemek için «acaba hangisine ilgi göstersem» diye bir seçme yapmak durumunda kalmaktadırlar. Daha başka bir deyișle, kitle haberleşme süreci diye adlandırdığımız süreç içinde gönderen ile alıcı arasında pek çok "seçme, reddetme», "kabul etme» ișlemleri olmaktadır.

Verdiklerini kabul ettirme durumuyla karşı karșıya bulunan gazete haberleri, radyo ve televizyon haber bültenleri bakımından girișilen rekabet, izleyici durumda bulunan kişilerin bunlara gönül-

(4) Wilbur Schramm, «The Nature of News», Journalism Quarterly, September 1949, s. 259.

(5) ibid. 
lï olarak ayıracağı zaman içinde kendini göstermektedir. Daha önce de dokunulduğu gibi, kișiler kişilikleri, yetiștikleri ortamın özelliklerine göre bunlar arasında bir seçme yapmaktadırlar. $\mathrm{Bu}$ arada, ayırabildikleri izleme süresi içinde de, kendilerini ilgilendiren haberleri araçlar yardımıyla almaktadırlar.

«Kişiler seçmeyi nasıl yapmaktadır,» «izleme süreleri kişilerin ne kadardır," «insanın ilgisini çeken haberler nelerdir» gibi yukarıdaki cümlelerde geçen soruların cevaplarını bulma ise, kișilerin özellikleri ile olduğu kadar, kişilerin haber almasını sağlayan gazeteler, radyo ve televizyon bakımından önemli konulardır. Zira, haber veren kuruluşlar olarak görev yapan gazeteler, radyo ve televizyon, özellikle verdikleri haberin ne kadarının kişilerce alındığı üzerinde, izleyicilerinin kimler olduklarını kestirebilmek bakımından önemle durmaktadırlar. Tabii, «izleyicileri» saptayabilmek, belirleyebilmek çok güçtür. Bununla beraber, «insanın ilgisini çekme» noktasından hareket ederek, her üç kitle haberleșme aracı da izleyicilere ulaşmağı amaçlamaktadırlar. Yalnız, ilk başta da değinildiği gibi, "radyo ve televizyon anilik ve çabukluk» özellikleri yanında, gazetelerin okuyucu bulması yönünde «insanın ilgisini çekme» daha güç koşullar altında gerçekleşmek durumuna gelmektedir.

\section{II - GAZETE OKUYUCUSUNUN ILGISİ ÜZERINNDE ARAŞ- TIRMALAR}

Radyo ve televizyonun gazetecilik yapması, bugünün gazetelerine hem çok şeyler kazandırmış hem de çok şeyler kaybettirmiştir. Radyonun çabuk olarak haberleri gerekli olduğu ölçüde yerinde kayda alınmıs seslerle vermesi, televizyonun ise haberleri resimlerle, filmlerle süslemesi, yanında, kișilerin duyduğu, gördüğü ha berleri, gazetede okumak bakımından içlerinde heves kalmasını temin etmek, radyo ve televizyonu geriden izleyen gazetelerin de ilk görevi olmuștur' Gazete hazırlanıp, basılıp kișilerin eline geçinceye kadar, kişiye göre çoktan tazeliğini yitirmiș haberleri nasıl ilginç kılmak mümkündür sorunu, gazeteler bakımından temel sorun olarak ön plâna çıkmıștır. Bu bakımdan, gazeteler kendilerini yenileme çabalarına girişmişlerdir. Kullanılan yenilikler bir yana, «ilginç kılmak» için büyük ödemelerin de yapılması gerekli olmuştur.

Daha radyo yeni yeni kullanılmağa bașlanıldı̆̆ı sıralarda, ga- 
atılmıştır. ${ }^{6} \mathrm{Bu}$ arada, A.B.D.'de yapılan çeşitli araştırmalarla gazete okuma üzerinde durulmağa bașlanılmıștır. ${ }^{7}$ Radyo izleme ile gazete okuma yoluyla, kişiler ve özellikleri incelenmiş, ayrıca her iki kitle haberleşme aracının kişiler üzerindeki etkileri ölçülmüştür. Televizyonun da yayına girmesiyle, aynı yönde araştırmalar televizyon bakımından da başlatılmıștır.

Kişilerin özellikleri ile, gazete okuma, radyo dinleme, televizyon izlemenin ilgili olduğunun ortaya konması bir yana, gazete haberleri arasında kișilerce neler okunduğu yönünde ilk adım 1930'da George Gallup tarafından atılmıștır. Gallup, nelerin okunduğunu saptamak bakımından bilimsel yönden okuyucunun ilgisini belirlemek için yöntemini geliștirmiștir.8 Bunun yanında, «haberler kișilere neler verir, neler kazandırır konusu üzerinde durmamıștır.

Gallup, "gazete okuyucusunun ilgisini gösteren bazı etkenlerin gazetelerin içinde» bulunduğu noktasından hareket ederek, "gazetelere gönderilen okuyucu şikâyet ve teşekkür mektuplarının, gazetelerin verdikleri ödüllerin, gazetelerin uyguladıkları anketlerin, ayrıca gazete tirajlarının, ilginin göstergesi olduğunu» ve bunların yazı ișleri müdürleri tarafından kabul edildiğini belirtmiștir.' Saydıkları gösterge olmakla beraber, Gallup gazete okuyucusunun ilgisini saptayabilmenin en kolay yolunun, "gazetenin son sayısı üzerinde çeșitli okuyucuların okudukları haberleri işaretlemek şeklinde olduğunu ${ }^{10}$ söyleyerek yöntemini ortaya atmıştır.

Gallup'un yöntemine göre, her denek için ayrı gazete kullanılarak, okudukları işaretlenerek, araștırmacının elde etmek istedik leri temin edilmek yoluna gidilmiștir. Bu yönteme dikkat edilecek olursa, gazetede nelerin okunduğu noktasından hareket ettiğinden tek boyutlu olduğu görülür. Daha başka deyişle, okuyucuların intibaları bu yöntemin uygulanmasında ișe karıșmaktadır.

Aslında, önemli olan sorun herhangi bir haberin ne kadarını ve ne uzunlukta olanının, ortalama bir gazete okuyucusu okumaktadır? Haberin neresinde okuyucu okumayı bırakmaktadır? Neden

(6) William A. Wood, Electronic Journalism - (New York: Columbia University Press, 1967) s. 10-11.

(7) Oya Tokgöz," Gazetecilik Araştırmalarının Önemi» SBF. Dergisi, cilt XXVII, No: 4 Ankara 1973, s. 88-90.

(8) George Gallup, «A Scientific Method to Determine Reader's Interest» Journalism Quarterly, March 1930, s. 1-13.

(9) ibid., s. $1-5$

(10) ibid., s. 5. 
birakıp okumamaktadır? Bu soruna da ilk parmak basan Wilbur Schramm olmuştur."1

Schramm, yaptırdığı okuyucu mülâkatlarında yine Gallup'un ve daha sonraları Advertising Research Foundation'un (Reklâm Araştırma Kurumu) ${ }^{12}$ geliştirdiği yöntemi kullanmıştır. Araştırmasının amacı yüzünden bazı değișiklikler yapması zorunlu olmuștur. ${ }^{13}$ Kendisi, yaptığı araştırmayı öncü araștırma (pilot study) olarak nitelemekle beraber, bulgularının bazıları oldukça ilginçtir. ${ }^{14}$

«1 - Bir haber baștaki ilk paragraflardan sonra okuyucu kaybetmektedir.

2 - Haber uzadıkça, okunma oranı küçük olmakla kalmayıp, çabuk okuyucu kaybetmektedir.

3 - Ortalama kişi, bir gazetenin tüm haberlerini $1 / 3$ ile $1 / 10$ arasında değișen bir şekilde okumaktadır.»

Gallup ve Schramm'in kişilerce neler okunur sorununu araştırmaları yanında, «neden, niçin, ne zaman ve nerede ?» gazete okunur sorularının da ilk sorunun ardından gelmesi gerekmektedir. Yani, "neleri» tanımlayabilmek için bir bakıma, "neden, niçin,» gibi insanın ilgisini gösteren soruların sorulması yoluyla mümkün olabilmektedir.

«Ne zaman» ve «nerede» soruları kișilerin gazete okumaya ayırdıkları zaman ve yeri göstermektedir. Belki gazete okuma bakımından, kimler, neden, niçin, ne zaman, nerede, neleri okurlar sorularını sormak, gazete okumanın neden insanın ilgisini çeken bir sorun olduğu üzerinde parmak basmanın en doğru yollarından bir tanesidir.

Son yargidan hareket eden, yine Wilbur Schramm, "haberleri insanlar bir karșılık bekleme umuduyla seçerler » ${ }^{15}$ görüșï, Gallup'un kişilerin neleri okuduklarını saptama amacıyla geliștirdiği yöntemi

(11) Wilbur Schramm, "Measuring Another Dimension of Newspaper Readership", Jcurnalism Quarterly, December 1947, s. 293.

(12) Advertising Research Foundation, 138 Study Summary, The Countinuing Study of Newspaper Reading, 5 Year Summary, 25 Western Hometown Daily and Newspaper Readership Studies conducted by Chilton R. Bush, Stanford University.

(13) Schramm, «Measuring Another Dimension of Newspaper Readership op. cit., s. 293-94.

(14) ibid., s. 295.

(15) Wilbur Schramm, "The Nature of News, cp. cit., s. 259. 
yanında, haberlerin kișilerce neden okunduğu sorununa bir karşlık bulmayı amaçlamaktadır. Schramm ve daha sonraları Herbert Kay, ${ }^{16}$ güdüsel yönden, "neden» sorusunun cevabını ararlarken, "rol teorisi ve algilama teorisi» ile bu soruya cevap bulmaya çalışanlar da olmuştur. ${ }^{17}$ Aslında, davranış̧̧ı açıdan geliștirilen araștırmalar yanında, bazı yapısal etkenler kișilerin gazete okumasina etkide bulunmaktadır.

Yapısal etkenlerin rolünü inceleyen ilk araștırma 1949 yılında Wilbur Schramm ve David M. White'in okuyucuların yaşlarının, cinsiyetlerinin, eğitim ve iktisadi durumlarının gazete okuma üzerinde etkileri olduğunu gösterebilmek için yapılmıştır. ${ }^{18}$ Birlikte giden değişkenler olarak adlandırılan yaș, cinsiyet, eğitim ve gelir bugün pek çok araştırmada olduğu gibi gazete okuma bakımından da büyük önem taşımaktadır. Schramm ve White'in yaptıkları yukarıda anılan araștırma ile ilk defa kișilerin yapısal özelliklerinin uboș zamanlarını değerlendirme» bakımından kullanılan bir araç olan gazete okuma yönünde etkisi üzerinde durulmuş olmaktadır.

Aslında, bu araştırma ile Schramm ve White kimlerin, neyi, nasıl, neden, niçin, nerede, ne zaman okuduklarını ancak yapısal etkenler dikkate alınarak ortaya konulabileceğini göstermek istemișlerdir. Bunun yanında, araștırmacılar, yaș eğitim, cinsiyet ve gelir durumunun, gazete okuma bakımından önemine işaret etmekle kalmayıp, kișilerin yapısal özellikleri düșïnülmeden gazete okuma üzerinde eğilmenin mümkün olamıyacağına da dokunmuşlardır. Ayrıca, aynı araștırma gazete okuma alıșkanlıklarını, kișilerin nasıl kazandığı ve diğer kitle haberleşme araçlarının verdikleri yanında çeșitli yaș gruplarında eğitim, gelir düzeyinde bulunan kișilerin gazetelere neden hevesli oldukları üzerinde de durmuștur. ${ }^{19}$

Gallup'un yukarıda anılan yönteminin güvenirliği yüksek olmakla beraber, araștırma sonucu olarak da bulunan gazete okuyucusu yüzdelerinin neleri ifade ettiği, ayrıca bunların çözümlenebileceği yönünden, sıklık dağılım (frequency distribution) ve faktör

(16) Herbert Kay, "Toward an Understanding of News Reading Behavior» Journ alism Quarterly 32 (1954) s. 15-32.

(17) Malcolm S. McLean Jr. "Research Planning» Nafziger ve White (der.) Introduction to Mass Communication Research - (Baton Rouge: Lousiana State University Press, 1958) s. 33-34.

(18) Wilbur Schramm, David M. White, «Age, Education and Economic Status. Factors in Newspaper Reading» Journalism Quarterly 26 (1949) s. $149-166$.

ibid., s. $155-56$. 
analizi (factor analysis) yolları kullanılmıștır. ${ }^{20} \mathrm{Bu}$ yolları deneyebilmek için, "gazetenin muhtevasının anlamlı kategorilere bölünmesinin gerektiğini »"1 söyleyen Nafziger, McLean Jr, Ensgtrom, "gazete okuyucusu araștırmalarının aslında denemeler (tests) niteliğinde olduğunu»22 ileri sürmüşlerdir.

Sıklık dağılımı yolunun, «yapılan denemeler üzerinde bir bakışta, haber konusu ile bir diğeri arasında okuyucular tarafından çekicilik bulunup bulunmadığını gösterdiğini»,23 yazarlar ifade etmişlerdir. Bunun yanında faktör analizi yolunun ise, «bir tip haber okuma ile diğer haber tiplerini okuma arasındaki farklılığı gösterdiğini, aynı zamanda bu yolun okuyucuların bazı durumlarda okuma özellikleri ile diğerleri arasındakileri özetleyebildiğini» ${ }^{24}$ de belirtilmişlerdir.

Gallup'un geliştirdiği yöntemle yapılan araştırmalar, orijinal yöntemin bazı aksakhklarını ortaya çıkarınca, A.B.D.'de Minnesota Üniversitesi Araştırma Bölümü yöntemin saha uygulaması bakımından bazı yenilikler getirmenin gerekli olduğunu ortaya koymuştur. ${ }^{25}$ Gallup'un orijinal yönteminde denek gazete okuyucusu için her seferinde araștırma için seçilen gazetenin son nüshası kullanılırken, ilk yenilik olarak, "araştırma için kullanılacak gazete nüshası yerine hazırlanmış işaretlenmiş gazete örneği (master copy) kullanılmasıdır. İkinci yenilik olarak, «daha önceden denek gaze te okuyucusunun verdiği cevapların yazılacağı standart veri kâğıdının hazırlanmasıdır». ${ }^{26}$

Aynı Üniversitece bundan sonra gerçekleştirilen yenilikler daha çok gazete okuyucuları için özel olarak hazırlanmış IBM kartlarının kullanılması ile verilerin analizi bakımından yapılmıștır. Saha uygulaması sırasında, toplanan veriler anında IBM kartlarına işlenerek, veriler toplanmış ve sonra analizine geçilmiștir. ${ }^{27}$

(20) Ralph N. Nafziger, Malcolm MCLean Jr., Warren Engstrom - "Useful tools for Interpreting Newpaper Readership Data» Journalism Quarterly, 28 (1958) s. 442.

(21) ibid.,

(22) ibid., s. 443.

(23) ibid., s. 444.

(24) ibid.,

(25) Robert L. Jones ve Leslie A. Beldo, "Methodological Improvements in Readership Data Gathering» Journalism Quarterly, 30 (1953) s. 347.

(26) ibid.

(27) ibid., s. 349. 
Minnesota Üniversitesince gazete okuyucusu araștırmalarının verilerinin toplanması bakımından yapılan iki büyük değișiklik daha bulunmaktadır. Bunlardan ilki, daha önce kodlanmıș veri kağıtlarının kullanılması, ikincisi ise, temel 80 sütünluk IBM kartlarının benimsenmesidir. ${ }^{28}$

Gallup'un geliștirdiği yöntem yanında Wilson L. Taylor'un okumayı ölçmek için geliştirdiği, aynı zamanda gazete okuma bakımindan kullanılabilen kapatma kuralı (cloze procedure) in anmadan geçmeyiz. ${ }^{29}$ Taylor, 'kapatma kuralı, haberleşmenin etkinliğini ölçebilme bakımından yeni bir psikolojik araçtır ${ }^{30}$ demekle beraber, kuralının amacı insan psikolojisinden hareket ederek insanın son okuduğu șeyi bütüne tamamladığını, mantıkî olarak boşluklari doldurduğunu varsaymaktadır..$^{31}$

Yukarıda anılan araștırmalardan da anlașılacağı üzere, Gallup hangi haberlerin okunduğu çı̆̆rını açmıș, Wilbur Schramm ise her haberden nekadarının okunduğuna eğilmiștir. Bu iki yönde de yapılanlar çok faydalı bulguların ortaya çıkmasına yol açmakla beraber, aslında ișin üçüncü boyutu olan kişilerin neden haberleri okuduğu daha doğrusu alıșkanlıkları üzerinde durmak gerekmektedir. Daha öncede değinildiği gibi, güdüsel yönden araștırmayı içeren bu boyut üzerinde araştırmalar olmakla beraber hâlâ da devam etmektedir.

\section{3 - Kișiler Neden Haberleri Okur?}

Daha önce de değinildiği gibi, Wilbur Schramm «kișiler haberleri bir karşılık bekleme umuduyla okurlar görüșü» ile gazete okumanın nedenine de parmak basmıștır. Karșılık beklemeyi Schramm, birdenbire karșilık bekleme (immediate reward), geciktirilmiş ola. rak karșılıklı bekleme (delayet reward) diye ikiye ayırmaktadır. ${ }^{32}$ Kendisi bu terimleri ortaya koyarken Freud'un mutluluk ve ger. çeklik ilkelerine dayandığını söylemektedir. Ayrıca, her kişi için bu

(28) ibid., s. 351.

(29) Wilson L. Taylor, "Cloze Procedure: A New Tool for Measuring Readability», Journalism Quarterly Fall 1953.

(30) ibid., 417.

(31) ibid., s. 415, Kuralın gelișmesi hakkında Bakınız: Wilson L. Taylor, "Recent Developments in the Use of "Cloze Procedure» Journalism Quarterly, 33 (1956), s. 42-48.

(32) Wilbur Schramm "The Nature of News» Journalism Quarterly - September 1949, s. 260. 
iki șekil karşılık beklemenin sınırının kararlı olmadığını, ancak genel anlamda varlıklarının kabul edilebileceğini eklemektedir. ${ }^{33}$

Aslında, kendisi haber seçimi bakımından psikolojik olarak nelerin meydana geldiğine de merak sarmıștır: "Birdenbire karșılık bekleme umuduyla haberi okuyanlar, sorunlarını çözmek veya basit anlamda öğrenmek için bunu yapmaktadırlar. Kișiye bir uyarı (haber) yapılmakta, buna karşılık bir cevap (haberi okumaya, dinlemeye, izlemeye karar verme) verilmekte ve cevap karşılanmaktadır. (merak, şüphe ortadan kalkmakta veya daha çok tatmin olunmaktadır). Daha başka bir deyișle birdenbire karșilık beklemede, kișiler okudukları ölçüde deneme ve hata yaparak öğrenmektedirler. Halbuki geciktirilmiş karşılık beklemede, haberi okumaya karar verme hoş olduğu için değil, gerçek olduğundan yapılmaktadir. » $^{34}$

«Íki tip haber, iki çeşit okuma șekli olduğunu kabul etsek» diyen Schramm, «her haber çeşidi içinde hangisinin seçileceğini neyin belirlendiğinin de» ${ }^{35}$ bulunması gereklidir, diye eklemektedir. «Genellikle, okuyucu kendini en çok ölçüde haberle özdeştirdiği yönde karșılık bekleme umudunun daha yüksek olması ve haberi okuması olasılığı vardır. $»^{36}$ șeklinde de «ne» yi tanımlamaktadır.

Güdüsel yönden araștırmayı amaçlayan «neden» sorusu, özellikle, güdüler, duygular, baskılar, gerilimler gibi kişilerin psikolojik yönünü kapsamakta olduğundan, gözlemleri güç olduğu nedeniyle cevap bulmanın zorlukları üzerinde durulmaktadır. Bu yönde araștırma yapmıș bulunanlardan biri olan Herbert Kay, ișe haberi bir süreç olarak tarif etmekle bașlamakta «haberle, haberi okuyan kimse arasında karşılıklı eylemleșme bulunduğunu» ${ }^{37}$ söylemektedir.

Kay, «bir haber sayısız elemandan meydana gelmektedir. Kelimeler, semboller șeklinde olanlar açıtır, normal görme yeteneklerine sahip kișilerce, bunlar, özdeș bir şekilde algılanmaktadırlar. Elemanların bazıları ise kağıt üzerinde basılı değildirler. Yalnız okuyucuların belleklerinde mevcutturlar. Kisacası, bunlar

(33) ibid., s. 261.

(34) ibid., s. 261

(35) ibid., s. 265.

(36) ibid.,

(37) Herbert Kay, op. cit., s. 16. 
okuyucunun önceki yaşam deneyimleridir, $\varkappa^{38}$ diye eklemektedir. Kay, bu sözleriyle, Schramm'n "The Nature of News" (Haberin Mahiyeti) adlı makalesinde ileri sürdüğ̈ görüsşlerine aynen katılmıș olmaktadır. ${ }^{39}$

Kay'in görüșlerine eklediği yeniliklere gelince bunlar şu şekilde özetlenebilir:

«Kişilerin haberlerden bir karșılık ummaları ancak haberi anlamaları ile mümkündür. Haber okurken bir karşılık beklemek, daha önce bilinmeyen bir şeyin ögrenilmesiyle temin edilebilir. ${ }^{40}$ Bun dan sonrada kişiler haberin, cazibesine «eğlenme, yakınlık, fayda güdüleri yoluyla» kapılabilirler. Yalnız, her güdü tipi iki yönlüdür. Olumlu tarafı cezbetmeyi, olumsuz tarafı ise reddetmeyi içermektedir. ${ }^{41}$

Yukarıda anlatılanlar bir yana, "neden haber okunur» sorusuna bir cevap bulma bakımından «eğitim» değişkeninin önemi üzerinde çok fazla durulmuştur. Zira, yapılan deneysel araștırmalar, iyi eğitim görmüș kişilerin kitle haberleşme araçlarından daha çok faydalandıklarını, ${ }^{42}$ değișik dergileri okuduklarını, ${ }^{43}$ değișik radyo ve televizyon programlarını izlediklerini, ${ }^{44}$ ortaya koymuş bulunmaktadır. Özellikle, bu araştırmalarda fazla eğitim görmüş kișilerin, daha az eğitim görmüş kişilere oranla, yazılı basını daha çok sözlü basını daha az izlediklerini, ayrıca eğitimin kitle haberleșme araçlarnna zaman ayırma ve bunu etkilemeyi de beraberinde getirdiği, «eğitimin kișilerin hayat görüșünü değiștirdiğini » ${ }^{45}$ de ortaya çıkmış bulunmaktadır.

Aslında gazeteler sosyal kurumlar olarak eskiden olduğu gibi, bugün de özellikle, radyo ve televizyonun baskısı dolayısıyla, beșeri

(38) ibid., s. 17.

(39) Wilbur Schramm, "The Nature of News», op. cit., s. 259.

(40) Kay, op. cit., s. 20 ve devami.

(41) ibid., s. 24 ve devami.

(42) Paul Lazarsfed, Bernard Berelson, Hazel Gaudet, The People's Choice, (N. Y, Columbia University Press, 1948). s. 120 ve devami.

(43) Paul Lazarsfeld, "Audience Research» Bernard Berelson and Morris Janowitz (der.) Public Opinion and Mass Communications, (Glencoe, Illinois, Free Press 1953,) s. 339.

(44) Bernard Berelson, Paul F. Lazarzfeld, William N. McPhee, Voting, (Chicago, The University of Chicago Press, 1954) s. 234 s. 234 ve devami.

(45) Merill Samuelson, Richard F. Carter, and Lee Ruggels, «Education, Available Time and Use of Mass Media» Journalism Quarterly, Autumn, 1963 s. 493. 
ve toplumsal temel ihtiyaçların yansıtılması görevini de yerine getirmek durumundadırlar. Bu bakımdan temel ihtiyaçlara cevap verebilmek için de kişilerin bunları okumasını temin etmek durumuyla karșı karşıyadırlar. Bu görevi yaparken de, ayrıca, kişilerin merakını tatmin etmeleri de gerekmektedir. Daha başka bir deyișle, sahte, düzensiz görüşler suridukları ölçüde gazeteler kișilerin ihtiyaçlarını karşılamaktan uzaklaşırlar ve okunma güçlerini yitirler. Gazeteler, bu duruma düşmemek bakımından, olaylar hakkında standard hüküm verme görevi yaparak, okuyucularını merak baskısından kurtarmak için çalışmalıdırlar.. ${ }^{46}$

Gazete okumanın bir nedeni olarak kişileri merak baskısından kurtarmanın gösterilmesi, kişilerin nasıl meraklarının uyandırılacağına bizi götürmektedir. Daha başka bir deyișle, gazetelere ve gezetecilere yine büyük bir iş düşmektedir. İșin bu yönüi ise, önce gazeteyi hazırlayanların yaratıcı güçlerini seferber etmelerini gerektirmektedir. Okunabilme için, neler yapalım ki, kișilerin merakı uyansın sorusuna cevap değil, kișilerin sorularına cevap bulmak için gayret sarfetmek durumundadirlar.

"Merak, șüphe, karmașıklık, nefret, korku, sevgi, așk» gibi insanın psikolojik yapısıyla ilgili kavramların kullanılması, özellikle geçen yüzyılın sonlarından itibaren gazetecilik açısından önem kazanmıștır. Dünyada okuma-yazma oranının artmasıla, yeni okuma öğrenen kişileri çekmenin bir yolu olarak yukarıda sayılan kavramlardan faydalanılarak, "sansasyon" diye anılan kavram ortaya atıl. mıștır. Bu kavramın hedefi, kişilerin duygularına hitap ederek, kișilerin ilgisini uyandırmaktır. Daha bașka bir deyişle, kișilere gerçekleri duygu dünyalarına büyük ölçüde ağırlık vererek sunmadır.

$\mathrm{Bu}$ yolun ilk uygulaması da kişilere dönük haber sunma yoluyla, onların sağlıklı haber almasını önlemek yoluyla başlatılmış. tır. Üstün nitelikli dramatik eserleri, ucuz melodramlar haline ge line getirip günlük olayların gerçekleri saptırılmıştır. "Sarı gazetecilik» diye adlandırlan bu akımı Amerika Birleșik Devletlerinde bașlatan Joseph Pulitzer ile William Randolph Hearst olmuștur. ${ }^{47}$

(46) Harold Mendelsohn, "Socio-Psychological Perspectives on the Mass Media and Public Anxiety» Journalism Quartely, Autumn 1963, s. 515516.

(47) Edwin Emery, Press and America, An Interpretative History of Journalism 2. baskı, (Englewood Cliffs, N. J., Prentice Hall, 1962)
s. 415 ve devamı. 
A.B.D.'de başlayan sansasyonla dolu gazetelerin çıkması akımı ile beraber, gazete türlerinde de değişiklikler görülmüștür. Amerika'da ve Anglo-Sakson ülkelerinde küçük formalı olarak çıkarılan tabloid adı verilen gazeteler sansasyonu ișlemişlerdir. Bol resimli, iri bașlıklı olarak hazırlanan bu tür gazeteler genel anlamda verdikleri haberlerle sokaktaki adamın sorunlarına hitap ettiklerini söylemișlerdir. Bu tür basın Avrupa'da bulvar basını adı altında varlığını sürdürmüștür.

Endüstri devriminin hılanması, bunun ardından I. Dünya Savaşının çıkması, dünyaya yayılması ile, dünyada ilk kez olarak savaş çok yerde görülmüsstür. Arkadan gelen büyük para bunalımı, II. Dünya Savaşının etkisi ile her şeyde olduğu gibi gazetecilikte de gerçekler ön plâna çıkmıştır. Hem gazeteleri hazırlayanlar hem de bunları okuyanlar bakımından gerçekler aranır olmuştur. Daha başka deyişle üzerinde durulan konular arasında savaşın kötülükleri, kan, ölüm, sefalet büyük yer tutar hale gelmiștir. Gerek gazeteler, gerekse de kișiler bu tip konuları yorumlanmış olarak öğretmek ve öğrenmek ister olmuşlardır.

Gazetelerin bu yola kaymalarında önce radyonun sonra da televizyonun büyük etkisi de bulunmaktadır. Bunların daha önce de değinilen özellikleri gazetelerin kendilerine yeni bir yol aramalarına yol açmıștır. Bunun yanunda, yine sansasyonla dolu gazeteler çıkmağa devam etmiștir. Hâlâ da etmektedir. Buna neden olarak da, modern hayatın monotonluğu içinde bunalan kişilerin hayatlarına renk katmak ve eğlendirme görevi yapmak gösterilmektedir.

Bütün bunlar bir ayna, gazetelerin yaptıkları yenilikler, değişiklikler de her okuyucunun ilgisini, merakını uyandırmayı hedef almakla beraber, okuyucunun ilgisini de devamlı olarak yenilenmekte, şekillenmekte, hattâ değișmektedir. Bu bakımdan, bir yandan artan konular yanında, gazeteler radyo ve televizyona ayak uydurmağa çalıșmakta, bir yandan da aynı zamanda okunabilmek için değişen okuyucu ilgilerine cevap bulmağa çabalamaktadırlar. 